\section{Racionamento dos cuidados de saúde: problemática inerente}

\author{
Rationing health care services: an inherent issue
}

\begin{abstract}
Limited resources in the health sector force a process of choice between alternative health care programs and services and patients or groups of patients who will receive care. In the absence of a price mechanism, the priority-setting process serves to allocate scarce resources among competing uses, and is thus a form of rationing. Traditionally, implicit approaches have dominated the health sector's decision-making, mostly by physicians. However, in the face of increasing budget constraints and rising patient expectations, more explicit and socially acceptable priority-setting practices are needed. Internationally, the development of explicit prioritization has proven difficult and controversial.
\end{abstract}

Financial Resources in Health; Health Priorities; Health Systems; Health Planning
Racionamento ou estabelecimento de prioridades (ambos os conceitos são usados como sinônimos no texto), dos cuidados de saúde envolve um processo de escolha entre programas e serviços alternativos de cuidados de saúde e entre pacientes ou grupos de pacientes. Na ausência de mecanismo de preços, nos sistemas de saúde públicos, para desempenhar o seu papel regulador no mercado, o racionamento aparece como seu substituto no processo de afetação dos recursos limitados.

O crescimento dos custos de saúde, acima do crescimento da riqueza dos países, coloca a necessidade de medidas explícitas de distribuição dos recursos de saúde na agenda política dos países desenvolvidos. Apesar do recente debate político e acadêmico, o racionamento dos cuidados de saúde não é um processo novo. Nenhum país dedicou à saúde recursos capazes de satisfazer toda a procura, pelo que o racionamento dos cuidados de saúde tem sido prática comum nos sistemas de saúde. As medidas de racionamento têm sido, no entanto, vagas, implícitas e desenvolvidas de forma discricionária e discreta pelos prestadores de cuidados de saúde. O que é novo no tema do racionamento é o debate sobre a necessidade de políticas explícitas e sistemáticas de racionamento, os modelos e métodos a adotar, o envolvimento público nas decisões e como conciliar esta realidade com a manutenção de sistemas públicos de saúde baseados nos princípios da universalidade na cobertura, eqüida- 
de no acesso e solidariedade no financiamento, valores, hoje, fundamentais nas sociedades desenvolvidas e democratas. O presente artigo foca alguns aspectos principais para a compreensão do processo de racionamento em curso.

\section{Racionamento implícito versus explícito}

O racionamento implícito dos cuidados de saúde, em particular o decorrente no nível da decisão clínica (bedside rationing), tem sido dominante nos sistemas públicos de saúde. Nesses modelos os médicos tomam decisões baseadas em critérios não publicamente definidos. As suas diferentes técnicas (p. ex.: seleção de doentes e lista de espera) podem não representar um racionamento consciencioso ou deliberado mas facilitam a vida daqueles que enfrentam restrições financeiras, de tempo ou de quaisquer outros recursos. O racionamento discricionário pressupõe que os clínicos recorrem aos seus próprios julgamentos de valor, assim como à sua experiência para decidirem que doentes devem receber intervenções e em que quantidade devem receber os cuidados de saúde. Isso tem a vantagem de dotar o processo de estabelecimento de prioridades e de afetação dos recursos de maior flexibilidade, ao mesmo tempo que tem sido acusado de promover decisões ineficientes e contrárias aos princípios da responsabilização democrática. Embora o racionamento implícito seja atualmente uma parte integrante das práticas de saúde, a literatura continua a compreender o debate em torno da sua aceitabilidade moral.

A introdução de critérios explícitos no racionamento transfere parte da responsabilidade que recai nos prestadores de cuidados de saúde para outros agentes, principalmente para os governantes. O esforço para definir critérios passa pelo desenvolvimento de princípios normativos e critérios técnicos que possam ser usados para incluir ou excluir pacientes da prestação de serviços, ou para incluir ou excluir programas da provisão legislativa, em substituição de práticas subjetivas dos médicos. O principal mérito do racionamento explícito é ser mais transparente e aberto à participação da sociedade. Contudo, deve imperar alguma cautela na limitação da liberdade discricionária dos médicos, sob pena de a heterogeneidade dos pacientes não ser considerada e se tratarem todos os indivíduos de forma idêntica.

Nenhum sistema de saúde aplica um método de racionamento puro. A maioria dos países ocidentais adota um sistema de racionamento misto, que envolve o estabelecimento implícito e explícito de prioridades.

\section{Níveis de decisão}

Nos sistemas de saúde públicos, as decisões de afetação dos recursos da saúde são feitas, basicamente, em dois níveis. Ao nível macro estabelecem-se prioridades entre programas de saúde. A conseqüência dessa decisão é que determinados tratamentos não sejam fornecidos e/ou publicamente financiados (como é o caso da maioria dos serviços de saúde oral, em Portugal). Ao nível micro são estabelecidas prioridades entre os pacientes. Os prestadores de cuidados de saúde enfrentam freqüentemente a dificuldade de decidir entre privilegiar a eficiência da distribuição, selecionando os doentes que têm um bom prognóstico ou, privilegiar a igualdade de hipóteses de acesso a todos que precisem de serviços médicos. A conseqüência mais habitual desse segundo nível de priorização é o desenvolvimento de listas de espera.

\section{Fundamentos éticos do racionamento}

As questões inerentes ao racionamento transportam-nos para o domínio da ética e da justiça distributiva. O estabelecimento de prioridades na prestação de cuidados de saúde significa tratar alguns doentes/doenças de forma preferencial, o que envolve além de aspectos puramente técnicos, julgamentos e dilemas morais. Não existe consenso na literatura sobre como deve ser entendido o conceito justiça distributiva em saúde. Os princípios mais comuns respeitam à afetação de acordo com a necessidade, mérito ou baseado no princípio do utilitarismo. A distribuição de acordo com a necessidade baseia-se na tradição Aristotélica de que justiça requer "tratar de forma igual o que é igual e de modo diferente o que é diferente". O princípio da distribuição de acordo com o mérito baseia-se no reconhecimento de que algumas características dos indivíduos devem merecer atenção especial na distribuição dos recursos. A visão utilitarista defende o primado da eficiência como regra de decisão para a distribuição dos recursos. De acordo com esse princípio os recursos devem ser distribuídos de forma a maximizar a utilidade (satisfação) esperada da sociedade.

Os diferentes princípios de justiça, implicam diferentes políticas de racionamento e todas têm dificuldades de implementação. Exatamente porque o racionamento deve ser baseado numa teoria de justiça, os processos de racionamento não podem, ou não devem, ignorar os valores da sociedade e a participação dos cidadãos. O reconhecimento de que a aceitação das medidas de racionamento é um dos principais 
aspectos a ter em conta no processo, generalizou os princípios da teoria comunitária (communitarianism). De acordo com o communitarianism, a sociedade não consegue lidar com questões de distribuição de recursos sem que os seus membros decidam questões normativas sobre a vida, a qualidade de vida e o papel da saúde. Os indivíduos são chamados a participar no debate como cidadãos em vez de consumidores individuais, pelo que a perspectiva adotada é a da sociedade.

\section{Metodologias técnicas de estabelecer prioridades}

A explicitação do estabelecimento de prioridades envolve o desenvolvimento e uso de critérios técnicos que têm como base as áreas da epidemiologia, economia e "medicina baseada na evidência" (MBE).

A contribuição da economia no estabelecimento de prioridades tem sido amplamente discutido na literatura de economia da saúde. A economia aborda o problema da afetação dos escassos recursos da saúde a partir da avaliação de custos e benefícios econômicos de programas e serviços alternativos. A questão da valorização dos resultados em saúde tem merecido uma vasta literatura na economia. Nos últimos anos tem-se generalizado o uso de uma medida que num só índice incorpora as duas principais dimensões da saúde, mortalidade (ganhos em quantidade) e morbidade (ganhos em qualidade) - Quality-Adjusted-Life-Years (QALY). Os QALY medem os anos de boa saúde (ano saudável) ganhos com um determinado tratamento. A análise custo-utilidade (ACU) prioriza os tratamentos por comparação entre custos e QALY's.

Apesar da preponderância que tem sido dada à ACU como instrumento para a tomada de decisões, a sua aplicação à priorização de doentes tem-se revelado duvidosa. O princípio utilitarista de maximização dos ganhos (em saúde) pode não ser consonante com a distribuição dos benefícios considerada desejável pela sociedade. A conjugação desses objetivos de eficiência e eqüidade é atualmente uma das maiores preocupações dos investigadores na área da economia da saúde.

O apelo a novos conhecimentos clínicos para avaliar a relativa eficácia ou ineficácia de diferentes intervenções é uma contribuição adicional a aplicar ao processo de racionamento. A literatura vem defendendo um modelo médico de prestação baseado na confirmação empírica da sua efetividade, de modo a generalizar as práticas que evidenciem o melhor compromisso custo-efetividade. Trata-se do modelo de MBE que ao identificar intervenções consideradas ineficazes reduz o desperdício enquanto libera recursos para usos alternativos, aligeirando a severidade associada ao racionamento.

Tal como as teorias de justiça, a abordagem técnica aos problemas do racionamento tem sérias limitações e problemas na aplicação. No entanto, contrariamente às teorias de justiça distributiva, que são mutuamente exclusivas, estas metodologias técnicas podem e devem complementar-se. A MBE ao fornecer novas informações científicas sobre a eficácia de intervenções alternativas pode complementar a ACU. De forma similar, a MBE pode beneficiar-se das avaliações econômicas desenvolvidas pela ACU.

\section{Experiências internacionais de estab- elecimento explícito de prioridades}

Nos últimos anos, alguns países ocidentais tentaram de forma sistemática determinar os critérios para definir uma cobertura de cuidados de saúde que responda aos princípios éticos que regem estas escolhas 1 . Os pioneiros nessa matéria são o Estado do Oregon (Estados Unidos), a Holanda, a Nova Zelândia, a Noruega e a Suécia. As experiências ilustram as dificuldades e os desafios do processo de racionamento explícito. Não existem ainda estudos capazes de avaliar o impacto total das políticas dos países europeus no controle de custos.

O Estado do Oregon constituiu o primeiro exercício explícito e organizado de estabelecer prioridades. O plano do Oregon teve a sua origem num episódio trágico de negação de um transplante (de medula óssea) que culminou na morte de uma criança. A racionalidade dessa decisão foi o alargamento do número de beneficiários do sistema Medicaid a todos os cidadãos em situação econômica elegível. Foi estimado que o não financiamento público de 34 transplantes libertaria recursos suficientes para incluir no programa 1.500 novos utentes. Nesse cenário, o preço de 34 vidas parecia tolerável. Esse episódio foi o ponto de partida para a definição de uma lista de cuidados de saúde a financiar publicamente. A metodologia desenvolvida envolveu a utilização de dados e valores sociais obtidos por audiências públicas e desenvolveu-se em três etapas. Na primeira, criou-se um ranking das combinações diagnóstico e de tratamento, com base no seu valor para a sociedade, o seu valor para o doente potencial e a sua importância para um pacote de serviços básicos. Na segunda etapa, recorreu-se à ACU, isto 
é, ao custo por QALY, para ordenar no interior de cada categoria os pares doença/tratamento. Por último, ponderaram-se os resultados segundo critérios de razoabilidade. Assim, se obteve, em 1991, uma lista de 709 pares doença/tratamento a serem cobertos pelos esquemas de proteção social dirigidos a pobres e idosos. Face ao teto orçamental para despesas públicas de saúde, decidiu-se financiar os primeiros 587 cuidados contemplados. Esta política revelou-se positiva, quer porque mais pessoas tiveram acesso ao programa Medicaid, quer pela diminuição do número de pacientes. Na revisão legislativa de 1993, os benefícios alargaram-se e a lista positiva compreendeu 696 casos. As dificuldades do Oregon e a discussão em torno das suas conseqüências ilustram as limitações da abordagem econômica tradicional, em particular a sua aceitação social.

O programa do Oregon mereceu a atenção internacional pela opção por um modelo que exclui serviços de saúde do financiamento público para alargar o leque de beneficiários. Semelhante trade-off é inviável em sistemas de saúde em que o acesso universal constitui um direito fundamental. Os países europeus tendem por isso a seguir modelos com maior ênfase na eqüidade do tratamento ao cidadão e na abordagem communitarianism.

A Holanda e a Nova Zelândia focaram o seu plano de racionamento na definição de um conjunto de serviços no qual reconhecem inaceitável o racionamento. A definição dos serviços a financiar publicamente seguiria a premissa "alguns cuidados para todos os indivíduos" em vez de "todos os cuidados para alguns". O Comitê Holandês, em 1992, propôs com base na abordagem comunitária, a criação de um pacote básico de serviços, onde cada tipo de "cuidado básico" é sujeito a múltiplos escrutínios: (i) ser necessário; (ii) ser efetivo; (iii) ser eficiente e; (iv) não passível de ser relegado à responsabilidade individual. Os critérios definidos atuavam como "filtros" e instituíam na sociedade holandesa a responsabilidade de ser solidária por cuidados de saúde comprovadamente necessários, cujos resultados se revelassem de fato benéficos, optando-se pelas práticas mais eficientes. Excluídos seriam todos os cuidados cujas razões de utilização pudessem ser individualmente atribuídas (p. ex.: fertilização in vitro). A Nova Zelândia seguiu também uma visão comunitária mas foi mais flexível na definição do pacote de cuidados básicos. Desde 1993 a decisão dos serviços financiados é feita por meio da aplicação de orientações clínicas que atentam nas circunstâncias de cada doente, em termos: (i) da possibilidade de produzir benefícios; (ii) do seu custo-efetividade; (iii) dos benefícios para a saúde da comunidade e; (iv) do respeito pelos valores da sociedade.

O modelo de racionamento nos países escandinavos é baseado na definição de princípios éticos básicos aceitos pela sociedade, inspirados nos valores cristãos e no humanismo ocidental. A Noruega foi não só o primeiro país a promover o racionamento dos cuidados de saúde como ainda o que o fez por motivos originais - evitar um surto inflacionista como conseqüência da descoberta de uma nova jazida de petróleo. A Comissão Norueguesa, em 1985, começou por definir a gravidade da condição médica como critério para o estabelecimento de prioridades. Em 1997, ao critério da eqüidade foi adicionado o da eficiência.

Na Suécia, a Comissão Parlamentar sobre Prioridades, em 1995, definiu com base em consultas populares e deliberações com peritos os seguintes princípios éticos subjacentes ao processo de estabelecer prioridades: (i) princípio da dignidade humana; (ii) princípio da necessidade e solidariedade, que pressupunha a concentração dos recursos onde as necessidades eram maiores, sendo dada especial atenção aos doentes mais vulneráveis e; (iii) princípio custo-efetividade. Segundo essa comissão, o princípio da dignidade humana precede os da solidariedade e da necessidade, enquanto o princípio econômico está subordinado aos dois anteriores. Ao definir critérios pouco rígidos e rejeitar critérios econômicos, a comissão reconheceu a inevitabilidade e os méritos da prática de algum racionamento implícito.

\section{Portugal e Brasil: problemática comum}

O Sistema Nacional de Saúde português (SNS) e o Sistema Único de Saúde brasileiro (SUS), ainda que instituídos com a defasagem de uma década, partilham das mesmas preocupações: a sistemática insuficiência de recursos para cumprir com os preceitos constitucionais e a fraca performance mesmo quando são afetados montantes consideráveis de recursos. Essa é a realidade em Portugal que, não obstante ser dos países com menor PIB do conjunto dos membros da União Européia, gastou em 2003, 9,6\% da riqueza criada em saúde 2 . Apesar dos gastos em saúde, o sistema de saúde é ineficiente e está longe de garantir a eqüidade 3 . No Brasil, pelo contrário, o principal problema parece ser a insuficiência de recursos canalizados para o sistema de saúde, quando comparados com outros setores (nomeadamente a Segurança Social). O Brasil gasta pouco com o setor da saúde quando 
comparado com outros países de desenvolvimento humano médio e, particularmente pouco, se comparado com países considerados desenvolvidos. Dados de 2003 indicam que o Brasil tem uma despesa, per capita, de US\$296,02, similar à do México, Chile, Costa Rica e Hungria, mas metade dos valores da Argentina e Uruguai. Os países mais desenvolvidos gastam aproximadamente US\$1.800, per capita 4 .

A continuidade dos sistemas públicos de saúde depende das políticas de racionamento que se venham a adotar. Racionamento, no sentido de estabelecimento de prioridades, não significa menos custos, mas sim uma melhor aplicação dos recursos. Nesse sentido, Portugal começa a dar os primeiros passos, em muito motivado pelo compromisso assumido pelo(s) governo(s) no Programa de Estabilidade e Crescimento (PEC). O orçamento de Estado para 2007 não exclui o SNS, que representa cerca de $22 \%$ da despesa pública corrente, do esforço nacional de equilíbrio das contas públicas. As reformas iniciadas protagonizam um SNS mais completo (por não deixar de fora os idosos); mais acessível (ao garantir médico de família a mais cidadãos); mais ágil (por evitar a proliferação de serviços redundantes); mais eficiente (ao reduzir o desperdício) e mais justo (concedendo prioridade por ordem de necessidade). O tema do racionamento explícito decorre necessariamente desses objetivos.

Apesar das realidades sociais serem diferentes, ambos os países têm nas experiências internacionais de racionamento em sistemas de saúde nacionais lições para as suas reformas e poderão enriquecer com a partilha das suas experiências.

\section{Conclusão}

Uma das questões centrais na literatura econômica sobre o racionamento é se este deve continuar a ser essencialmente discricionário ou se deve antes assumir um caráter explícito. Optando pela segunda hipótese é preciso questionar como deve o estabelecimento explícito de prioridades ser prosseguido.

Não obstante as experiências internacionais, parece que o dilema em torno do estabelecimento explícito de prioridades continua sem solução à vista. Os modelos internacionais devem ser encarados menos como soluções acabadas e mais como um esforço que vem sendo feito no sentido de desenvolver um modo de distribuição de recursos mais transparente, justo e eficiente. Ham 5 usa uma metáfora desportiva para referir que o processo de estabelecer explicitamente prioridades se assemelha mais a uma maratona que a um sprint.

Uma importante conclusão a retirar é que é necessário definir uma estratégia de estabelecimento de prioridades que passe por utilizar uma metodologia suficientemente eclética capaz de incorporar técnicas e debates públicos 5 . Para que o processo de priorização dos cuidados de saúde seja legítimo, todos os atores sociais devem ser envolvidos numa tentativa de minimizar conflitos de interesse. Nas sociedades modernas os cidadãos situam-se no centro do modelo de prestação de cuidados de saúde. Por isso, devem ser ouvidos sobre os cuidados prestados e as suas opiniões e preferências devem ser respeitadas, tentando satisfazer as suas legítimas necessidades. Adicionalmente, a definição dos valores éticos que regem uma sociedade são essenciais para clarificar a natureza do potencial trade-off que pode surgir com o estabelecimento de prioridades. 


\section{Resumo}

A escassez de recursos que caracteriza os sistemas de saúde obriga a tomada de decisões de priorização que se traduzem em escolhas entre programas/serviços alternativos e/ou entre pacientes ou grupos de pacientes. Na ausência de mecanismo de preços, o estabelecimento de prioridades consagra uma forma de afetação dos escassos recursos no mercado dos cuidados de saúde, traduzido em racionamento. Tradicionalmente, nos sistemas de saúde públicos as decisões de afetação dos recursos têm sido tomadas de forma discricionária, sobretudo pelos médicos. Contudo, a crescente limitação dos recursos, associada a um aumento das expectativas por parte dos doentes, apela a formas mais explícitas de racionamento legitimadas socialmente. Internacionalmente, o desenvolvimento de processos explícitos de priorização tem-se revelado difícil e controverso.

Recursos Financeiros em Saúde; Prioridades em Saúde; Sistemas de Saúde; Planejamento em Saúde

\section{Referências}

1. Ham C, Robert G. Reasonable rationing: international experience of priority setting in health care. Berkshire: Open University Press; 2003.

2. Instituto de Gestão Informática e Financeira. Relatório de contas, 2003. Lisboa: Instituto de Gestão Informática e Financeira; 2003.

3. Dixon A, Mossialos E. Has the Portuguese NHS achieved its objectives of equity and efficiency? Int Soc Secur Rev 2000; 53:49-78.

4. Guichard S. The reform of the health care system in Portugal. Paris: Organisation for Economic Cooperation and Development; 2004. (Economics Department Working Papers, 405).

5. Ham C. Priority setting in health care: learning from international experience. Health Policy 1997; 42:49-66.

Recebido em 08/Nov/2006 Aprovado em 13/Jun/2007 